\title{
Numerical Simulation of the SrZrO3 Formation in Solid Oxide Fuel Cells
}

\author{
Cheng, Kaiming; Xu, Huixia; Zhang, Lijun; Du, Yong; Zhou, Jixue; Tang, Shouqiu; Chen, Ming
}

Published in:

Journal of Electronic Materials

Link to article, DOI:

10.1007/s11664-019-07236-0

Publication date:

2019

Document Version

Peer reviewed version

Link back to DTU Orbit

Citation (APA):

Cheng, K., Xu, H., Zhang, L., Du, Y., Zhou, J., Tang, S., \& Chen, M. (2019). Numerical Simulation of the SrZrO3 Formation in Solid Oxide Fuel Cells. Journal of Electronic Materials, 48(9), 5510-5515.

https://doi.org/10.1007/s11664-019-07236-0

\section{General rights}

Copyright and moral rights for the publications made accessible in the public portal are retained by the authors and/or other copyright owners and it is a condition of accessing publications that users recognise and abide by the legal requirements associated with these rights.

- Users may download and print one copy of any publication from the public portal for the purpose of private study or research.

- You may not further distribute the material or use it for any profit-making activity or commercial gain

- You may freely distribute the URL identifying the publication in the public portal 


\title{
Numerical simulation of the $\mathrm{SrZrO}_{3}$ formation in solid oxide fuel cells
}

Kaiming Chenga,b,*, Huixia Xub,c, Lijun Zhang ${ }^{\mathrm{c}}$, Yong $\mathrm{Du}^{\mathrm{c}}$, Jixue Zhou ${ }^{\mathrm{a}}$, Shouqiu Tang ${ }^{\mathrm{a}}$, Ming Chen $^{\text {b,* }}$

a Shandong Provincial Key Laboratory for High Strength Lightweight Metallic Materials, Advanced Materials Institute, Qilu University of Technology (Shandong Academy of Sciences), Jinan 250014, China

b Department of Energy Conversion and Storage, Technical University of Denmark, Risø campus, Roskilde 4000, Denmark

c State Key Laboratory of Powder Metallurgy, Central South University, Changsha 410083, China

*Corresponding author: minc@dtu.dk (M. Chen), chengkaimingtry@gmail.com (K.M. Cheng)

\begin{abstract}
The $\mathrm{Ce}_{1-x} \mathrm{Gd}_{x} \mathrm{O}_{2-\delta}$ (CGO) interlayer is a common reaction barrier layer employed in solid oxide fuel cells (SOFCs), to prevent chemical reactions between the $\left(\mathrm{La}_{1-x} \mathrm{Sr}_{x}\right)\left(\mathrm{Co}_{1-y} \mathrm{Fe}_{y}\right) \mathrm{O}_{3-\delta}$ (LSCF) cathode and the $\mathrm{Y}_{2} \mathrm{O}_{3}$-stabilized $\mathrm{ZrO}_{2}$ (YSZ) electrolyte. However, even with the existence of the CGO layer, formation of $\mathrm{SrZrO}_{3}(\mathrm{SZO})$ insulating phase can still take place, causing cell degradation. Considering there have been already a large amount of experimental investigations conducted on the above degradation phenomenon, the current work is attempting to numerically model the process. A simplified numerical model of SZO formation at the YSZ-CGO interface is constructed. Based on the thermodynamic information and diffusion kinetics of the YSZ-CGOLSCF system from the literature, the interdiffusion between YSZ and CGO, the Sr diffusion through the CGO layer, and the formation of SZO at the YSZ-CGO interface are modelled, reproducing the experimental data well. Limitations of the current modeling work are further discussed.
\end{abstract}


Keywords: Solid oxide fuel cells; Cathode degradation; YSZ-CGO interdiffusion; $\mathrm{SrZrO}_{3}$ formation; Numerical simulation

\section{Introduction}

The iron- and cobalt-containing perovskites, i.e. $\left(\mathrm{La}_{1-x} \mathrm{Sr}_{x}\right)\left(\mathrm{Co}_{1-y} \mathrm{Fe}_{y}\right) \mathrm{O}_{3-\delta}$ (LSCF), exhibit high electronic and oxygen ion conductivity and have been shown as a high-performance cathode material for solid oxide fuel cell (SOFC) applications at the so-called intermediate operating temperatures between $600{ }^{\circ} \mathrm{C}$ and $800{ }^{\circ} \mathrm{C}$ [1]. Considering that LSCF perovskite can easily react with the $\mathrm{Y}_{2} \mathrm{O}_{3}$-stabilized $\mathrm{ZrO}_{2}$ (YSZ) electrolyte at high temperature to form oxide ion insulators, e.g. $\mathrm{La}_{2} \mathrm{Zr}_{2} \mathrm{O}_{7}$ and $\mathrm{SrZrO}_{3}(\mathrm{SZO})$ [2], an interlayer or so-called reaction barrier layer consisting of $\mathrm{Ce}_{1-x} \mathrm{Gd}_{x} \mathrm{O}_{2-\delta}$ (CGO) is normally required to avoid such hazardous interface reactions $[3,4]$. However, even with a CGO interlayer, the SOFC cell degradation can still take place in the YSZCGO-LSCF region, partly caused by the YSZ-CGO interdiffusion during sintering of the CGO layer and SZO formation at the YSZ-CGO interface during cathode sintering and long-term cell operation. Generally, the CGO interlayer should be as dense as possible to maximize its protective effect as diffusion barrier, which on the other hand requires a higher sintering temperature, resulting in a thicker YSZ-CGO inter-diffusion zone with low ionic conductivity [5, 6]. Therefore, a tradeoff must be made between reducing YSZ-CGO interdiffusion during CGO layer sintering and controlling SZO formation during cathode sintering and cell long-term operation, and the selection of fabrication method and sintering temperature for the CGO interlayer is of particular importance.

So far, a large number of experimental investigations have been conducted on the SZO 
formation with different heat-treatment conditions for the CGO layer and several common findings have been reported [6-15]. When CGO is sintered below $1200{ }^{\circ} \mathrm{C}$, sintering the LSCF cathode at $1100{ }^{\circ} \mathrm{C}$ for $2 \mathrm{~h}$ results in a SZO layer covering the YSZ electrolyte surface entirely. When the sintering temperature of the CGO interlayer is above $1300{ }^{\circ} \mathrm{C}$, the amount of SZO formed during cathode sintering (at $1100{ }^{\circ} \mathrm{C}$ for $2 \mathrm{~h}$ ) decreases with increasing CGO sintering temperature and the SZO grains tend to distribute dispersedly, i.e. not as a continuous layer [14]. However, in the case of CGO sintered at $1300{ }^{\circ} \mathrm{C}$, with prolonging cathode sintering time up to $16 \mathrm{~h}$, SZO can still cover the YSZ electrolyte surface entirely as presented by Matsuda et al. [15]. With regard to cell performance, latest studies $[8,13]$ further demonstrate that in the case of screen-printed CGO layer, heat treatment of CGO at high temperature to reduce SZO formation can compensate the losses caused by lower ionic conductivity of the YSZ-CGO interdiffusion zone. Considering the extensive experimental results reported so far, it is of urgent need to perform theoretical analysis in order to obtain deeper understanding of these phenomena and possibly help optimize the cell fabrication process. The current work is thus devoted to reproducing the experimental results in the frame of thermodynamic and kinetic modeling, with a focus on simulating formation and growth of SZO at the YSZ-CGO interface.

\section{Methodology}

\subsection{CALPHAD method}

The basic idea for the CALculation of PHAse Diagram (CALPHAD) approach is to describe the thermodynamic properties of each phase in a system with a mathematical model containing adjustable parameters, which can be evaluated by optimizing the fit of the model to all the experiential information. It is then possible to recalculate the phase diagram as well as the 
thermodynamic properties of all the phases. [16]. The Compound Energy Formalism (CEF) [17] is widely used in CALPHAD modeling, which is introduced to describe the Gibbs energy for all the phases in the current YSZ-CGO-LSCF system. However, it is an extensive project to establish the thermodynamic database for the complete Zr-Y-Ce-Gd-La-Sr-Co-Fe-O system, which is also unnecessary for the current simulation. In the current work, the YSZ-CGO-LSCF system is simplified to a model system as $\mathrm{ZrO}_{2}-\mathrm{CeO}_{2}-\mathrm{SrO}$, taking into account the $\mathrm{Zr}$ and Ce interdiffusion between YSZ and CGO, the Sr diffusion through the CGO layer, and the formation of SZO at the YSZ-CGO interface.

\subsection{Grain boundary diffusion model}

The kinetic modeling is carried out using the Thermo-Calc \& DICTRA software [18-20]. Thermo-Calc is a powerful tool for phase equilibrium calculations, whereas DICTRA is a software package for simulation of diffusional reactions in multicomponent alloys. Thermal-Calc \& DICTRA together can reveal a good coupling between thermodynamic information and diffusion kinetics, i.e. thermodynamic database and diffusion coefficients (atomic mobility). In the current simulation, the grain boundary model in DICTRA [21-23] is employed to account for the contribution of grain boundary diffusion in both of the YSZ and CGO region, to be consistent with experimental observation. According to the model, the grain boundary diffusion is correlated to the bulk diffusion by using the same frequency factor of $D_{0}^{\text {bulk }}$, but a modified bulk activation energy of $Q^{\text {bulk }}$, as specified by the equation below,

$$
D^{g b}=D_{0}^{b u l k} \cdot \exp \left(F \cdot \frac{Q^{b u l k}}{R T}\right)
$$


where $D^{g b}$ is the contribution of grain boundary diffusivity and $F$ is the bulk diffusion activation energy multiplier. The total diffusivity including both bulk and grain boundary diffusion is then formulated as:

$$
D^{\text {total }}=\frac{\delta}{d} \cdot D^{g b}+\left(1-\frac{\delta}{d}\right) \cdot D^{b u l k}
$$

where $\delta$ and $d$ are the grain boundary thickness and the grain size, respectively.

\section{Results and Discussion}

\subsection{Thermodynamic and diffusion kinetic data}

Based on the above simplification, the CALPHAD-type modeling of phases that should be included in the current thermodynamic database are cubic $\mathrm{ZrO}_{2}$ [24], $\mathrm{CeO}_{2}$ [24], $\mathrm{SrO}$ [25] and $\mathrm{SrZrO}_{3}$ [26]. Attention should be drawn to the thermodynamic modeling of cubic $\mathrm{ZrO}_{2}$, where cubic structure is not stable without the existence of $\mathrm{Y}_{2} \mathrm{O}_{3}$ in YSZ. In order to describe the cubic $\mathrm{ZrO}_{2}$ phase in the current modeling, the metastable thermodynamic parameters of cubic phase in the $\mathrm{ZrO}_{2}-\mathrm{CeO}_{2}$ system presented by $\mathrm{Du}$ et al. [24] is adopted. Besides, the thermodynamic parameters for other phases are directly acquired form literature and no higher order parameter is adjusted to the $\mathrm{ZrO}_{2}-\mathrm{CeO}_{2}-\mathrm{SrO}$ system. The available elemental bulk diffusion coefficients are adopted from literature, including Ce in YSZ [27], Zr in YSZ [28], Sr in CGO [29] and Zr in SZO [30]. Due to lack of experimental data, it is assumed in the current work that the diffusivities of $\mathrm{Zr}$ and Ce in CGO are the same as those in YSZ.

\subsection{Numerical modeling}




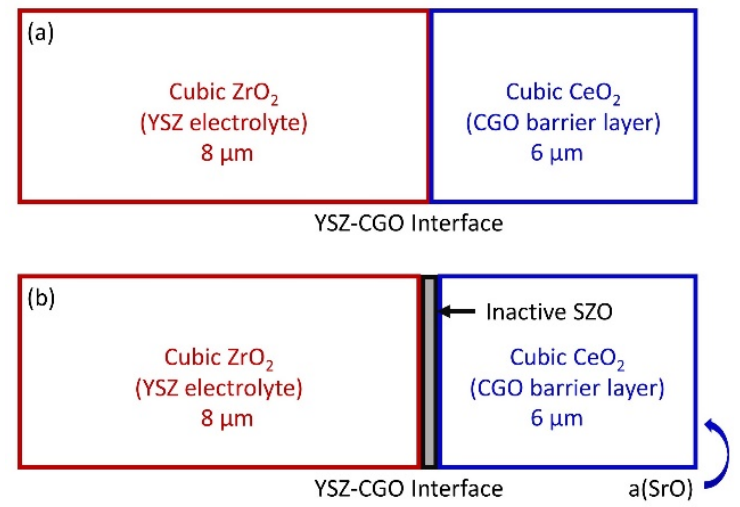

Fig. 1. Schematic illustration of (a) the model system for simulating interdiffusion between YSZ and CGO and (b) the model system for simulating the formation of SZO at the YSZ-CGO interface.

Figure 1a provides a schematic illustration of a one-dimension (1D) diffusion couple of $\mathrm{ZrO}_{2}-\mathrm{CeO}_{2}$ as set up in our recent work [31] mimicing the YSZ-CGO interdiffusion at various temperatures between $1373 \mathrm{~K}$ and $1673 \mathrm{~K}$. Based on the parameters employed in actual cell production [32], in the current work, the thickness of CGO and YSZ layer is set to be 6 and $8 \mu \mathrm{m}$, respectively. A typical sintering time of $3 \mathrm{~h}$ is selected, simulating the processes happening during cathode sintering. In Figure 1b, a boundary condition was set to the right boundary of the $\mathrm{CeO}_{2}$ layer, defining the activity of SrO as that in LSCF. An initially inactive SZO phase is defined at the YSZ-CGO interface to allow its formation. Knibbe et al. [33] investigated in detail on whether the formation of SZO at the YSZ-CGO interface is reaction limited or diffusion limited. By comparing the grain-boundary diffusion coefficient of Sr in CGO and the thickness of CGO barrier layer, they concluded that under the condition of steady-state Sr diffusion, the growth of SZO can be reasonably assumed to be diffusion limited. We hence consider an immediate reaction to form SZO when Sr reaches the YSZ-CGO interface, and the reaction time for the formation of SZO is negligible. The grain boundary diffusion model is activated using the same parameters determined 
as in our previous modeling work of the YSZ-CGO interdiffusion [31]. During kinetic simulation, the CALPHAD-type thermodynamic database of the $\mathrm{ZrO}_{2}-\mathrm{CeO}_{2}-\mathrm{SrO}$ system is coupled to DICTRA to guarantee the local thermodynamic equilibrium, while the diffusion flux and the diffusion depth are determined by the elemental diffusivity.

\subsection{Interdiffusion between YSZ and CGO}

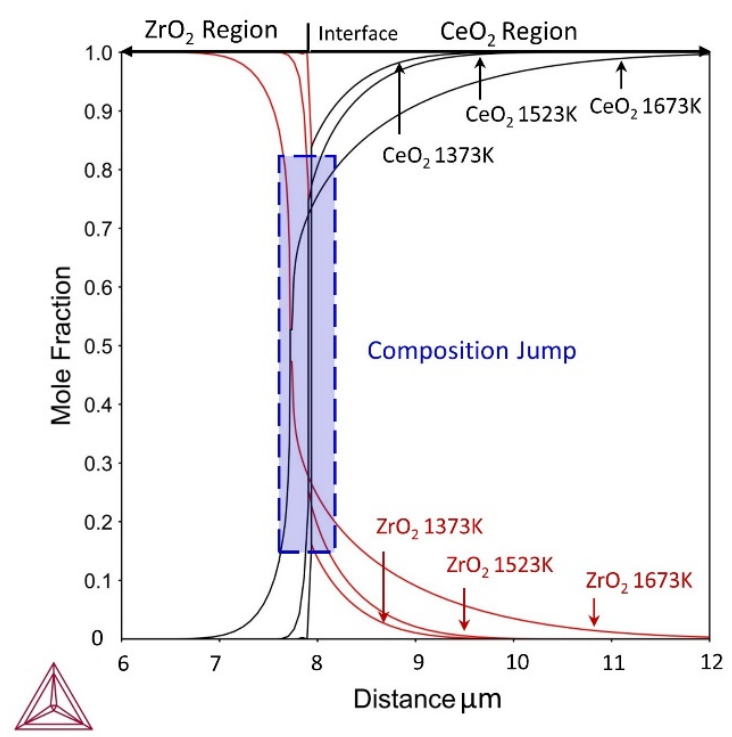

Fig. 2. Simulated composition profiles of the $\mathrm{ZrO}_{2}-\mathrm{CeO}_{2}$ diffusion couple sintered at $1373 \mathrm{~K}$, $1523 \mathrm{~K}$ and $1673 \mathrm{~K}$ for $3 \mathrm{~h}$ using parameters from Xu et al. [31].

Considering our recent experimental and simulation work on the interdiffusion between YSZ and CGO [31], the parameters of Eq. 2 in the current simulation are selected accordingly. It should be mentioned that in our DICTRA simulation the grain size in the CGO layer is set to be constant over time, but varies with temperature, $0.1 \mu \mathrm{m}$ at $1373 \mathrm{~K}, 0.5 \mu \mathrm{m}$ at $1523 \mathrm{~K}$ and $1 \mu \mathrm{m}$ at 1673K. These values are chosen based on the CGO layer microstructure after sintering as presented 
in [8]. Fig. 2 plots the simulated composition profiles at different heat treatment temperatures for $3 \mathrm{~h}$. It should be noticed that the $x$ axis applied in Fig. 2 focuses only on a small region at the $\mathrm{ZrO}_{2}$ $\mathrm{CeO}_{2}$ interface, where the interdiffusion zone can be detected. It can be seen that the element diffusion in the $\mathrm{CeO}_{2}$ layer is faster than that in the $\mathrm{ZrO}_{2}$ layer, and the interdiffusion zone becomes thicker with increasing temperature as expected. The composition jump at the $\mathrm{ZrO}_{2}-\mathrm{CeO}_{2}$ interface is a result of the miscibility gap existing in the $\mathrm{ZrO}_{2}-\mathrm{CeO}_{2}$ system.

\subsection{Growth of SZO at the YSZ-CGO interface}

(a)

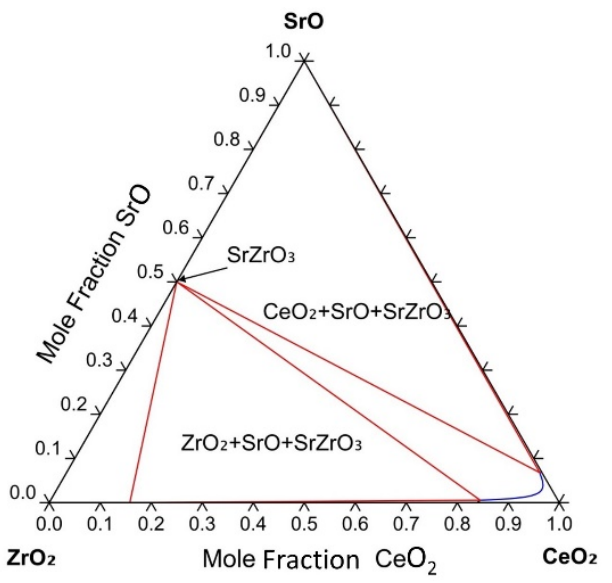

(b)

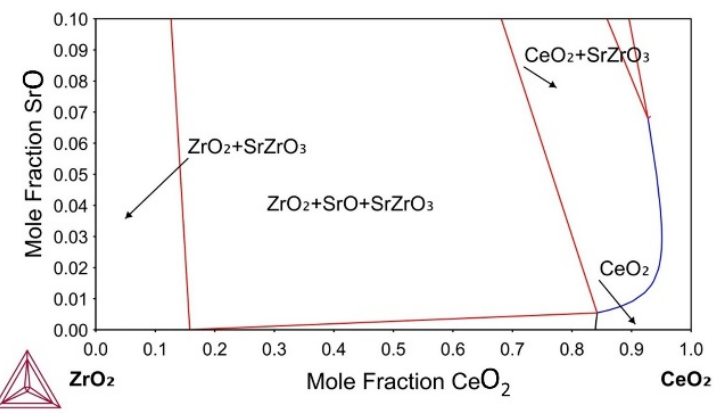

Fig. 3. Calculated (a) $\mathrm{ZrO}_{2}-\mathrm{CeO}_{2}-\mathrm{SrO}$ isothermal section at $1373 \mathrm{~K}$ and (b) an enlargement in the composition range of $0 \sim 10$ at.\% SrO.

Figure 3 shows the calculated metastable phase diagram of the $\mathrm{ZrO}_{2}-\mathrm{CeO}_{2}-\mathrm{SrO}$ isothermal section at $1373 \mathrm{~K}$ from the current work and an enlargement in the composition range of 0-10 mol \% SrO. The initial composition of each end-member in the current simulation (i.e. $\mathrm{ZrO}_{2}$ and $\mathrm{CeO}_{2}$ ) lies in the cubic $\mathrm{ZrO}_{2}$ and $\mathrm{CeO}_{2}$ single phase region, respectively. A boundary condition was set to the right boundary of the $\mathrm{CeO}_{2}$ layer, defining the activity of $\mathrm{SrO}$ as that in LSCF. From a 
thermodynamic point of view, as the amount of Sr increases, the overall composition of the entire diffusion couple can reach to a point located inside the $\mathrm{ZrO}_{2}+\mathrm{SrO}+\mathrm{SrZrO}_{3}$ three-phase region. The inactive $\mathrm{SrZrO}_{3}$ layer set initially at the YSZ-CGO interface can then be activated to form and grow with time. The sintering temperature and time in the current simulation (simulating cathode sintering) are $1373 \mathrm{~K}$ and $3 \mathrm{~h}$, respectively. In order to describe the grain boundary diffusion, the same set of parameters for simulating the YSZ-CGO interdiffusion are used. For simplification, the current simulation is performed at $1373 \mathrm{~K}$ only, which does not include the process where the YSZ-CGO bilayer is first sintered at high temperature. However, in order to reveal the dependence of SZO formation on the heat-treatment temperature of the CGO layer, different CGO grain sizes of $0.1 \mu \mathrm{m}, 0.5 \mu \mathrm{m}$ and $1 \mu \mathrm{m}$ are introduced to represent the microstructure change after the YSZCGO interdiffusion at 1373K, $1523 \mathrm{~K}$ and $1673 \mathrm{~K}$. The difference in grain size can then affect both the Sr diffusion across CGO layer and the growth of SZO at the YSZ-CGO interface.

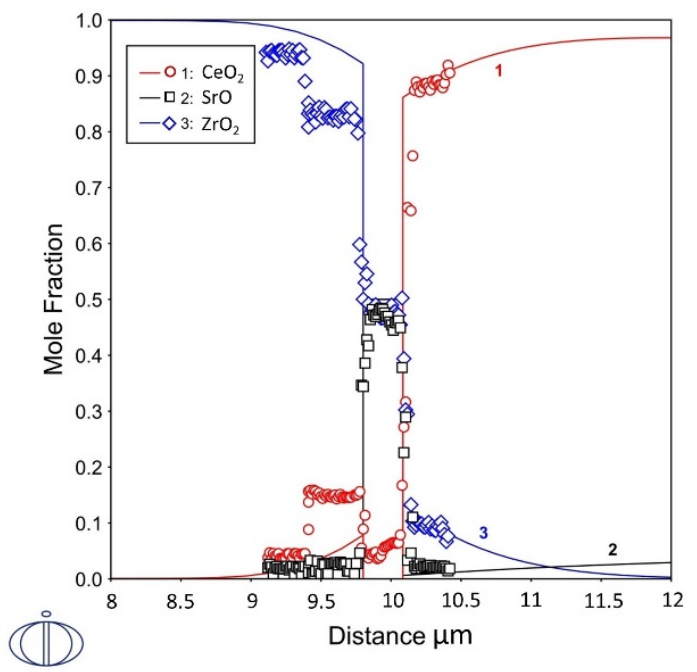

Fig. 4. Comparison between the simulated composition profiles (lines) at $1373 \mathrm{~K}$ for $3 \mathrm{~h}$ (CGO grain size $0.1 \mu \mathrm{m}$ ) from the current work and the experimental line-scanning data from Wilde 
et al. [8] (symbols).

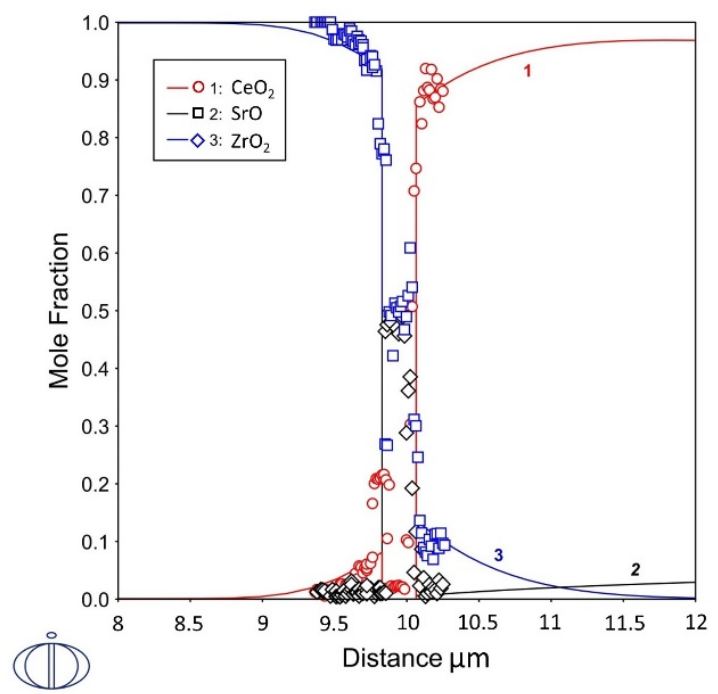

Fig. 5. Comparison between the simulated composition profiles (lines) at $1373 \mathrm{~K}$ for $3 \mathrm{~h}$ (CGO grain size $0.5 \mu \mathrm{m}$ ) from the current work and the experimental line-scanning data from Wilde et al. [8] (symbols).

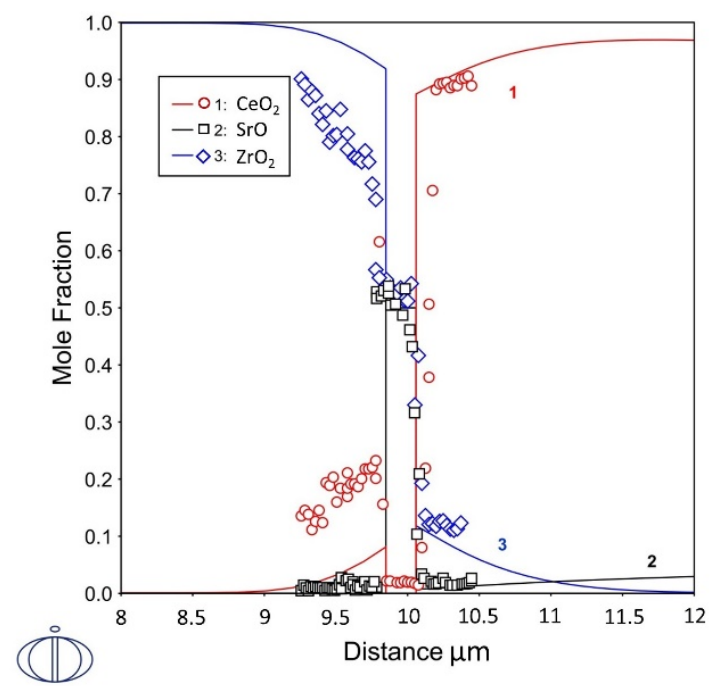

Fig. 6. Comparison between the simulated composition profiles (lines) at $1373 \mathrm{~K}$ for $3 \mathrm{~h}$ (CGO grain size $1 \mu \mathrm{m}$ ) from the current work and the experimental line-scanning data from Wilde et al. [8] (symbols). 


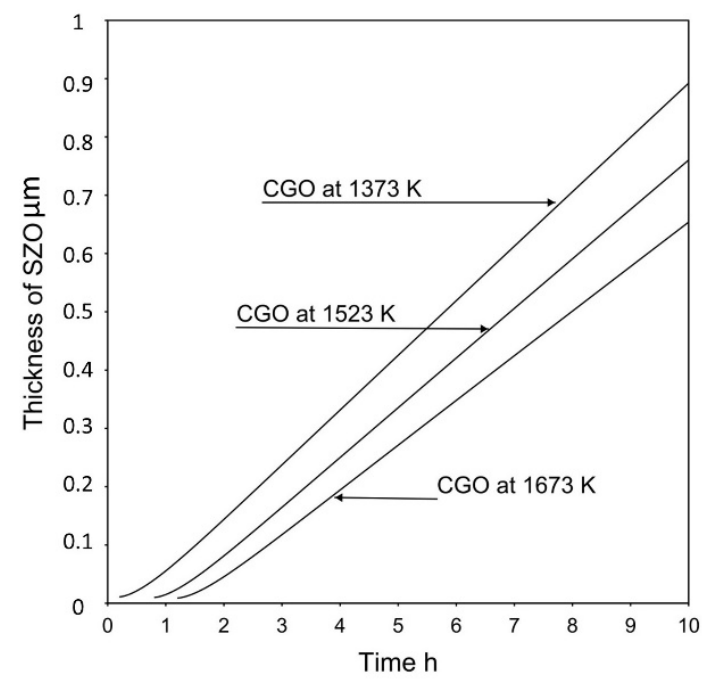

Fig. 7. Calculated SZO layer thickness vs. time for CGO layers sintered at different temperatures.

Figures 4-6 present the simulated composition profiles in comparison with the experimental line-scanning data [8]. The current simulation can only handle formation of a continuous thin SZO layer at the YSZ-CGO interface as observed by Wilde et al. [8], but not possible to model appearance of dispersed SZO reported previously [6-15]. The simulated SZO layer thickness decreases with increasing the grain size in the CGO region, indicating that the ability of the CGO layer as Sr diffusion barrier is enhanced when increasing CGO sintering temperature. Fig. 7 shows a plot of the SZO layer thickness vs. time under different conditions. It can be seen that the growth rate of SZO decreases with increasing the CGO sintering temperature, i.e. the higher the CGO sintering temperature, the larger the CGO grain size, the less the $\mathrm{Sr}$ diffusion via grain boundaries. For the same reason, the starting point for the first appearance of $\mathrm{SZO}($ as $l(\mathrm{SZO})=10 \mathrm{~nm})$ is postponed with increasing the CGO sintering temperature, as shown in Fig. 7. It is, however, interesting to notice that a linear relationship exists between the thickness of the formed SZO layer and time in such a diffusion-controlled situation. This indicates that the limiting factor for the growth of SZO is the amount of Sr diffuse through the CGO region, which 
is a constant due to the existence of the CGO diffusion barrier layer.

\section{Summary}

The formation of a SZO thin layer at the YSZ-CGO interface is numerically modeled in the current work. The YSZ-CGO-LSCF system is simplified to $\mathrm{ZrO}_{2}-\mathrm{CeO}_{2}-\mathrm{SrO}$, taking into account the $\mathrm{Zr}$ and Ce interdiffusion, the transportation of Sr and formation of SZO. The simulation of the SZO formation and growth at the YSZ-CGO interface is then performed with further simplifications. No temperature- or time-evolution of the grain size is considered in this work. However, different grain size in the CGO layer is introduced to represent the effect of CGO sintering temperature on the formation of SZO. Simplification is also made by considering the YSZ-CGO interdiffusion only during the cathode sintering, not during the CGO layer sintering. Further assumption is made to ignore the dispersed distribution of SZO grains, but to consider a continuous thin layer of SZO. However, even with the simplifications mentioned above, the current simulation result can still qualitatively describe the SZO formation and reproduce some of the experimental data well. Further improvement on the model is needed to be able to quantitatively predict the YSZ-CGO interdiffusion and SZO formation and optimize the sintering parameters based on the results.

\section{Acknowledgement}

The support from National Natural Science Foundation of China (Grant No. 51801116), Natural Science Foundation of Shandong Province (No. ZR2017BEM022) and Youth Fund of Shandong Academy of Sciences (2018QN0032) is acknowledged. This work is further supported by European Horizon 2020 - Research and Innovation Framework Programme (H2020-JTI-FCH- 
2015-1) under grant agreement n735918 (INSIGHT project).

\section{References}

[1] A. Mai, V.A.C. Haanappel, S. Uhlenbruck, F. Tietz, and D. Stöver, Solid State Ionics 176, 1341 (2005).

[2] H.Y. Tu, Y. Takeda, N. Imanishi, and O. Yamamoto, Solid State Ionics 117, 277 (1999).

[3] H. Uchida, S. Arisaka, and M. Watanabe, Electrochem. Solid State Lett. 2, 428 (1999).

[4] A. Tsoga, A. Gupta, A. Naoumidis, and P. Nikolopoulos, Acta mater. 48, 4709 (2000).

[5] T. Horita, N. Sakai, H. Yokokawa, M. Dokiya, T. Kawada, J.V. Herle, and K. Sasaki, J. Electroceramics 1, 15 (1997).

[6] A. Mai, V.A.C. Haanappel, F. Tietz, and D. Stöver, Solid State Ionics 177, 2103 (2006).

[7] A. Tsoga, A. Gupta, A. Naoumidis, D. Skarmoutsos, and P. Nikolopoulos, Ionics 4, 234 (1998).

[8] V. Wilde, H. Störmer, J. Szász, F. Wankmüller, E. Ivers-Tiffée, and D. Gerthsen, ACS Appl. Energy Mater. (2018) DOI: 10.1021/acsaem.8b00847.

[9] N. Jordan, W. Assenmacher, S. Uhlenbruck, V.A.C. Haanappel, H.P. Buchkremer, D. Stöver, and W. Mader, Solid State Ionics 179, 919 (2008).

[10] S. Uhlenbruck, T. Moskalewicz, N. Jordan, H.-J. Penkalla, and H.P. Buchkremer, Solid State Ionics 180, 418 (2009).

[11] F. Wang, M. Nishi, M.E. Brito, H. Kishimoto, K. Yamaji, H. Yokokawa, and T. Horita, J. Power Sources 258, 281 (2014).

[12] R. Kiebach, W. Zhang, W. Zhang, M. Chen, K. Norrman, H.-J. Wang, J.R. Bowen, R. Barfod, and P.V. Hendriksen, J. Power Sources 283, 151 (2015).

[13] J. Szasz, F. Wankmüller, V. Wilde, H. Störmer, D. Gerthsen, N.H. Menzler, and E. Ivers-Tiffée, 
ECS Trans. 68, 763 (2015).

[14] F. Wankmüller, J. Szasz, J. Joos, V. Wilde, H. Störmer, D. Gerthsen, and E. Ivers-Tiffée, J. Power Sources 360, 399 (2017).

[15] J. Matsuda, S. Kanae, T. Kawabata, J.-T. Chou, Y. Inoue, S. Taniguchi, and K. Sasaki, ECS Trans. 78, 993 (2017).

[16] H. Lukas, S.G. Fries, and B. Sundman, Computational Thermodynamics: The Calphad Method, Cambridge University Press, New York (2007).

[17] M. Hillert, J. Alloys Compd. 320, 161 (2001).

[18] J.-O. Andersson, T. Helander, L. Höglund, P. Shi, and B. Sundman, CALPHAD 26, 273 (2002).

[19] J.-O. Andersson and J. Ågren, J. Appl. Phys. 72, 1350 (1992).

[20] A. Borgenstam, A. Engström, L. Höglund, and J. Ågren, J. Phase Equilib. 21, 269 (2000).

[21] S. Hallström, L. Höglund, and J. Ågren, Acta Mater. 59, 53 (2011).

[22] N. Ta, L. Zhang, Q. Li, Z. Lu, and Y. Lin, Corros. Sci. 139 (2018) 355-369.

[23] N. Ta, M. Chen, L. Zhang, C. Chatzichristodoulou, W. Chen, P. V. Hendriksen, and Y. Du, J. Membrane Sci. 548, 526 (2017).

[24] Y. Du, M. Yashima, T. Koura. M. Kakihana, and M. Yoshimura, Scr. Mater. 31, 327 (1994).

[25] D. Risold, B. Hallstedt, and L.J. Gauckler, CALPHAD 20, 353 (1996).

[26] W. Gong, T. Chen, Y. Liu, D. Li, Z. Jin, and B. Huang, Trans. Nonferrous Met. SOC. China 17, 739 (2007).

[27] M. Kilo, G. Borchardt, B. Lesage, O. KaõÈtasov, S. Weber, and S. Scherrer, J. Eur. Ceram. Soc. 20, 2069 (2000).

[28] V.M. Bekale, A.M. Huntz, C. Legros, G. Sattonnay, and F. Jomard, Philos. Mag. 88, 1 (2008).

[29] M. Izuki, M.E. Brito, K. Yamaji, H. Kishimoto, D.-H. Cho, T. Shimonosono, T. Horita, and 
H. Yokokawa, J. Power Sources 196, 7232 (2011).

[30] R. Sažinas, I. Sakaguchi, M.-A. Einarsrud and T. Grande, Inorganics 6, 14 (2018).

[31] H. Xu, M. Chen, K. Cheng, L. Zhang, K. Brodersen and Y. Du, (2019) unpublished.

[32] A. Hauch, K. Brodersen, M. Chen and M.B. Mogensen, Solid State Ionics 293, 27 (2016).

[33] R. Knibbe, J. Hjelm, M. Menon, N. Pryds, M. Søgaard, H. Wang and K. Neufeld, J. Am.

Ceram. Soc. 93, 2877 (2010). 